\title{
Sleepless in COVID-19: how not to lose sleep in lockdowns
}

\author{
Siddharth Raj Yadav, Rohit Kumar, Amit Kumar, Pranav Ish, Nitesh Gupta, Shibdas Chakrabarti \\ Department of Pulmonary, Critical Care and Sleep Medicine, Safdarjung Hospital, New Delhi, India
}

To the Editor

The coronavirus disease 2019 (COVID-19) outbreak started in December 2019 in Wuhan, China, and spread all over the world leading to declaration of a pandemic by World Health Organization (WHO) on $11^{\text {th }}$ March 2020. Most countries around the world have enforced lockdown in an effort to halt the spread of virus. People around the world have been pushed into uncharted waters of uncertainty, fear, anxiety, stress and depression due to economic crash down, job losses and fear for their own health and that of their loved ones.

There is a known association between anxiety/stress and sleep disturbances and vice versa. The most vulnerable population in this isolation like condition, in this lockdown, are the chief earning member of the family, women, young ones, and people with psychiatric illness $[1,2]$. Health care workers should also be considered in this high-risk population, in times of this pandemic, as they are under constant stress and sleep deprived due to long duty hours. Stress related sleep problems are common [3]. All individuals naive to stress-related sleep disruption are likely to develop

Correspondence: Siddharth Raj Yadav, Department of Pulmonary, Critical Care and Sleep Medicine, Safdarjung Hospital, New Delhi, India.

E-mail: drsid28@gmail.com

Funding: No funding support was taken for the conduct of the study.

Conflict of interest: The Authors declare no conflict of interest relating to the study.

Contributions: All the authors made a substantive intellectual contribution. All the authors have read and approved the final version of the manuscript and agreed to be accountable for all aspects of the work in ensuring that questions related to the accuracy or integrity of any part of the work are appropriately investigated and resolved.

Key words: COVID-19; sleep; insomnia; sleep disturbance.

Received for publication: 8 May 2020.

Accepted for publication: 8 June 2020.

${ }^{\circ}$ Copyright: the Author(s), 2020

Licensee PAGEPress, Italy

Monaldi Archives for Chest Disease 2020; 90:1364

doi: 10.4081/monaldi.2020.1364

This article is distributed under the terms of the Creative Commons Attribution Noncommercial License (by-nc 4.0) which permits any noncommercial use, distribution, and reproduction in any medium, provided the original author(s) and source are credited. insomnia (acute or chronic). Post-traumatic stress disorders (PTSD) are more common in people with insomnia when exposed to sizable stressors such as COVID-19 pandemic. In Wuhan, it was observed that nearly $7 \%$ of population mainly women, those in the younger age group and those following news on COVID-19 for more than $3 \mathrm{~h}$ per day had higher levels of anxiety and PTSD [4]. In contrast, those with better sleep and fewer awakenings had less PTSD symptoms [5].

The possible sleep related challenges during isolation in lockdown are due to severance in daily life, due to a profound change in normal routine, i.e. work from home, school/college closure, social distancing and quarantine. Adapting to a new daily schedule is difficult. Time tracking and even remembering days of the week can be cumbersome if daily chores, i.e. going to gym, visiting churches and temples, dropping kids to nursery and going to office are not followed. Individuals who are working from home or those whose working hours have been reduced due to COVID-19 tend to over sleep during the day time leading to disruption in their eating habits, and this makes them groggy and irritable throughout the day.

The circadian rhythm that plays a key role in keeping us awake during the day, and makes us sleepy at night is disrupted due to confinement in homes during lockdown which leads to poor exposure to natural light during the day. Use of mobile phones, tablets and computers to watch news, binge watching of web series and connecting on social media lead to excessive screen time in evening hours. The blue light emitted from screens can suppress the natural production of melatonin, which plays a key role in inducing sleep naturally. Bright light exposure during the day gives better melatonin increase during the night.

Activity levels during the day also affect sleep pattern; low levels of activity (whether due to confinement or depression) affect sleep negatively, as do strenuous activity (e.g. due to stress or work overload). Physical activity during the day (but not late at night) improves sleep quality [6,7]. Disrupted circadian rhythm has psychological and somatic effects (Table 1).

The psychological effects are more pronounced in people with a history of substance abuse [8,9]. Alcohol, opium and marijuana addicts when kept confined in homes without the supply tend to get violent. Home abuse and domestic violence are common in such homes leading to fear and poor sleep quality [10]. This is an important issue that needs to be addressed urgently; if not done, the entire family, the basic unit of our society is bound to be doomed, socially, somatically and psychologically.

Sleep is one of the most important biological processes for all living beings; it becomes more important while defending against COVID-19 pandemic as it offers wide range of benefits. It intensifies the immune system, improves brain function, enhances mood and improves mental health.

People who are suffering from sleep related problems such as insomnia (acute/chronic) during COVID-19 led lockdown can be benefited with cognitive-behavioural treatment of insomnia (CBT- 
Table 1. Long term effects of disrupted circadian rhythm and insomnia.

\begin{tabular}{ll} 
Somatic effects & Psychological effect \\
High blood pressure, loss of libido & Depression \\
Uncontrolled diabetes, acid reflux disease & Memory loss \\
\hline Weight gain, decreased immunity & Impulsive behaviour \\
Worsening of respiratory drive & Mood swings \\
\hline
\end{tabular}

Table 2. Suggestion for better tackling of sleep problems during COVID-19 pandemic and lockdown for different populations.

$\begin{array}{lll}\text { General population } & \text { Women and children } & \text { High burdened professionals (police/HCW) } \\ \text { - Maintain regular sleep and wake time } & \text { - Avoid gender gap, share responsibilities } & \text { - Express your stress and concerns to friends, vent } \\ \text { - Talk of stress and vent out } & \text { - Maintain the sleep time pattern of children } & \text { out briefly } \\ \text { - Bedroom only for sleep and sex } & \text { - Engage children in calming and enjoyable } & \text { - Keep busy in free time with exercise and yoga, avoid } \\ \text { - Follow natural sleep pattern } & \text { activities 1 h before bed time } & \text { at night } \\ \text { - Use social media for distracting thoughts of } & \text { - Avoid gadgets after dinner } & \text { - Avoid excessive listening to news } \\ \text { - coronavirus by humour } & \text { - Stop children from using smart phones and } & \text { - Get natural day light, keep work place bright } \\ \text { - Find a hobby and enjoy } & \text { tablets in bed } & \text { - Eat correct and at correct time } \\ \text { - Limit news time on coronavirus } & \text { - Reassure children, help them emotionally } & \text { - Take short naps, if experiencing fatigue, lack of } \\ \text { - Keep home clean, cool and comfortable } & \text { - Avoid sharing bed with child } & \text { sleep and irritability at work place } \\ \text { - Keep home well-lit and bright during the day } & \text { - Engage child in creative activities } & \text { - Avoid driving after long shifts } \\ \text { - Keep lights dim in evening hours } & \text { - Comfortable room leads to a comfortable } & \\ \text { - Meditate, yoga and exercise during day time } & \text { child } & \\ \text { - Control calorie count } & & \\ \text { - Avoid food and gadgets } 2 \text { h before sleep } & & \end{array}$

I) [11]. It has been found that CBT is one of the leading, effective and accessible treatments which serves to treat insomnia (acute/chronic) due to rapid stress-causing situation such as COVID- 19 pandemic and long lockdowns [7,12]. Many constituents of this healing methodology could be applied to the current situation world over.

Few suggestions for better tackling of sleep problems during COVID-19 pandemic and lockdown are summarized in Table 2.

\section{References}

1. Taylor MR, Agho KE, Stevens GJ, Raphael B. Factors influencing psychological distress during a disease epidemic: Data from Australia's first outbreak of equine influenza. BMC Public Health 2008;81:347.

2. Jeong H, Yim HW, Song YJ, et al. Mental health status of people isolated due to Middle East Respiratory Syndrome. Epidemiol Health 2016;38:e2016048.

3. Altena E, Micoulaud-Franchi JA, Geoffroy PA, et al. The bidirectional relation between emotional reactivity and sleep: From disruption to recovery. Behav Neurosci 2016;130:336-50.

4. Huang Y, Zhao N. Generalized anxiety disorder, depressive symptoms and sleep quality during COVID-19 outbreak in China: a web-based cross-sectional survey. Psychiatry Res 2020;288:112954-.
5. Liu N, Zhang F, Wei C, et al. Prevalence and predictors of PTSS during COVID-19 outbreak in China hardest-hit areas: Gender differences matter. Psychiatry Res 2020;287:112921.

6. Fuller PM, Gooley JJ, Saper CB. Neurobiology of the sleepwake cycle: sleep architecture, circadian regulation, and regulatory feedback. J Biol Rhythms 2006;21:482-93.

7. Potter GD, Skene DJ, Arendt J, et al. Circadian rhythm and sleep disruption: causes, metabolic consequences, and countermeasures. Endocr Rev 2016;37:584-608.

8. Roehrs TA, Roth T. Sleep disturbance in substance use disorders. Psychiatr Clin North Am 2015;38:793-803.

9. Sahu K, Sahu S. Substance abuse: causes and consequences. Bangabasi Acad J 2012;9:52-61.

10. Rukmini S. Locked down with abusers: India sees surge in domestic violence [Internet]. Available from: https://www. aljazeera.com/news/2020/04/locked-abusers-india-domesticviolence-surge-200415092014621.html

11. Baglioni C, Altena E, Bjorvatn B, et al. The European Academy for Cognitive Behavioural Therapy for Insomnia: An initiative of the European Insomnia Network to promote implementation and dissemination of treatment. J Sleep Res 2020;29:e12967.

12. Randall C, Nowakowski S, Ellis JG. Managing acute insomnia in prison: evaluation of a "one-shot" cognitive behavioral therapy for insomnia (CBT-I) intervention. Behav Sleep Med 2019;17:827-36. 